\title{
Altitude Scaling of Thermal Ice Protection Systems in Running Wet Operation
}

\author{
D.M. Orchard ${ }^{1}$ \\ National Research Council Canada, Ottawa, Ontario, Canada \\ H. E. Addy ${ }^{2}$ \\ NASA Glenn Research Center, Cleveland, Ohio, 44135 \\ W. B. Wright ${ }^{3}$ \\ Vantage Partners, LLC, NASA Glenn Research Center, Cleveland, Ohio, 44135 \\ and \\ J. Tsao ${ }^{4}$ \\ Ohio Aerospace Institute, NASA Glenn Research Center, Cleveland, Ohio, 44135
}

\begin{abstract}
A study into the effects of altitude on an aircraft thermal Ice Protection System (IPS) performance has been conducted by the National Research Council Canada (NRC) in collaboration with the NASA Glenn Icing Branch. The study included tests of an airfoil model, with a heated-air IPS, installed in the NRC's Altitude Icing Wind Tunnel (AIWT) at altitude and ground level conditions. Two scaling strategies were employed based on Reynolds number and Weber number approaches that were combined with matching the ratio of water loading and evaporative rates. The Reynolds number scaled conditions resulted in greater mass of accreted ice that formed further back from the leading edge while the Weber number approach provided a close matches to reference altitude conditions in terms of both ice mass, location and shape.
\end{abstract}

\section{Nomenclature}

$\begin{array}{lll}\mathrm{C}_{\mathrm{p}, \mathrm{a}} & = & \text { constant-pressure specific heat of air } \\ \mathrm{d} & = & \text { twice the model leading edge radius } \\ \mathrm{D}_{\mathrm{v}} & = & \text { diffusivity of water vapour } \\ \mathrm{h}_{\mathrm{c}} & = & \text { convective heat transfer coefficient } \\ \mathrm{h}_{\mathrm{g}} & = & \text { convective mass transfer coefficient } \\ \mathrm{IPS} & = & \text { ice protection system } \\ \mathrm{k}_{\mathrm{a}} & = & \text { thermal conductivity of air } \\ \mathrm{K}_{0} & = & \text { modified inertia parameter } \\ \mathrm{LWC} & = & \text { liquid water content } \\ \mathrm{m}_{\mathrm{e}} & = & \text { mass flux of water evaporated } \\ \mathrm{MVD} & = & \text { median volumetric diameter } \\ \mathrm{m}_{\mathrm{w}} & = & \text { water loading } \\ \mathrm{Pr} & = & \text { Prandtl number } \\ \mathrm{P}_{\mathrm{w}} & = & \text { vapour pressure of water over liquid water }\end{array}$

${ }^{1}$ Senior Research Officer, Aerodynamics Laboratory, 1200 Montreal Road, Ottawa, Canada, AIAA senior member

${ }^{2}$ Aerospace Engineer, Icing Branch, 21000 Brookpark Rd., MS 11-2, AIAA Associate Fellow

${ }^{3}$ Aerospace Engineer, Icing Branch, 21000 Brookpark Rd., MS 11-2, AIAA Senior Member

${ }^{4}$ Principal Research Scientist, Icing Branch, 21000 Brookpark Rd., MS 11-2, AIAA Associate Fellow 


$\begin{array}{lll}\mathrm{P}_{\mathrm{ww}} & = & \text { vapour pressure of water in the atmosphere } \\ \mathrm{P}_{\infty} & = & \text { static air pressure } \\ \mathrm{q}_{\mathrm{c}} & = & \text { surface heat loss due to convection } \\ \mathrm{Re} & = & \text { Reynolds number } \\ \operatorname{Ref} & = & \text { Reference conditions } \\ \operatorname{Re}-2 \pi \mathrm{r} & = & \text { Reynolds number based on leading edge diameter } \\ \mathrm{Re} \mathrm{sc} & = & \text { Reynolds number scaled conditions } \\ \mathrm{Sc} & = & \text { Schmidt number of air } \\ \mathrm{T}_{\mathrm{r}} & = & \text { recovery temperature } \\ \mathrm{T}_{\mathrm{stati}} & = & \text { static temperature } \\ \mathrm{T}_{\text {surface }} & = & \text { surface temperature } \\ \mathrm{V} & = & \text { true air speed } \\ \mathrm{We}_{\mathrm{a}} & = & \text { Weber number based on air density } \\ \mathrm{We}_{\mathrm{w}} & = & \text { Weber number based on water density } \\ \beta_{0} & = & \text { collection efficiency at stagnation } \\ \gamma & = & \text { ratio of specific heats for air } \\ \mu_{\mathrm{a}} & = & \text { air viscosity } \\ \rho_{\mathrm{a}} & = & \text { air density } \\ \rho_{\mathrm{w}} & = & \text { water density } \\ \sigma_{\mathrm{w}} & = & \text { surface tension, water-air } \\ \tau & = & \text { exposure time to icing cloud } \\ \pi_{3} & = & \text { ratio of water loading to mass of ice that evaporates }\end{array}$

\section{Introduction}

A ircraft encounters with icing conditions pose a major threat to flight safety, with the resulting build-up of ice on exposed surfaces leading to higher drag, degradation of control authority and stall occurring at higher speeds and lower angles of attack. To counter this threat, many aircraft employ Ice Protection Systems (IPSs) that use thermal energy to prevent the build-up of ice on critical surfaces such as leading edges of wings and engine nacelles.

With advances towards more efficient aircraft, all systems are being re-examined in terms of reducing their energy requirements. With a thermal IPS, energy reduction can be achieved by operating in a 'running wet' mode under more extreme icing conditions. In a running wet mode, the water impinging on the protected surface is warmed only enough to allow it to run completely off the aircraft or back to a noncritical area before freezing. This requires significantly less energy than operating in a mode where all the impinging water is removed through evaporation [Addy et al., 2016].

In order to ensure a running wet system can provide the necessary protection throughout the range of icing conditions to be encountered, a thorough evaluation of the energy requirements is needed. To do this, a combination of experimental, e.g., wind tunnel, and simulation studies are performed that replicate the icing environment using a range of conditions that will impact the severity of the in-flight icing, such as air temperatures, air speed, Liquid Water Content (LWC), Median Volumetric Diameter (MVD) and the altitude at which the encounter is expected to occur. Many icing wind tunnel facilities, however, do not have the capability to simulate altitude conditions and, therefore, have to rely on scaling methods to approximate the altitude effects on the operation of the IPS. Various methods of scaling for altitude effects have been proposed and used [Whalen et al., 2005, 2007] [Papadakis et al., 2008], [SAE, 2014], but a vigorous validation so as to produce a widespread acceptance of any one of them has not been achieved. A better understanding of the processes involved in thermal IPS operation at altitude is needed to develop a validated and more widely accepted altitude scaling method. This, in turn, will enable more exact design, testing and evaluation of these systems [Addy et al., 2016].

This issue has been examined through a series of collaborative studies between the National Research Council (NRC) Aerodynamics Laboratory and the National Aeronautics and Space Administration (NASA), which undertook an in depth assessment of scaling methods for altitude effects of IPS operation. Conducted over three test campaigns in 2012 [Addy et al., 2013], 2014 [Addy et al., 2016] and 2015, the NRC's Altitude Icing Wind Tunnel was used to test a 2D NACA 0018 airfoil (designed and manufactured by NASA) that included a piccolo tube to supply hot air to the inside of the airfoil leading edge in order to simulate an IPS.

The AIWT is capable of simulating an in-flight icing environment through the control of air speed, icing cloud spray (with variation of both liquid water content and drop size), temperature and altitudes from sea level up to 
40,000 ft. The model was instrumented to measure the flow rate of the heated air through the piccolo tube as well as the surface temperatures over the leading edge region of the model.

As mentioned above, this collaborative study was performed over three test campaigns, the first of which examined a scaling technique based on heat transfer, droplet impingement, water loading and recovery temperature similarity. With this scaling approach, it was shown that while the airfoil surface temperatures and thermal IPS heat energy were well matched between altitude and sea level, the total amount of ice accretion as well as the chordwise location of the ice was not. As a result, the second campaign was undertaken to examine the significance of water drop movement over the leading edge of the airfoil. This was driven by observations made in the first campaign where water drop re-entrainment into the flow was seen from the top of the ice rivulets. In addition, previous studies [Olsen and Walker, 1997], [Kind and Oleskiw, 2001], [Kind, 2001] and [Feo, 2001] had reported the significance of runback water movement related aircraft icing. The alternative scaling method implemented in the second campaign was to match the Weber number [Addy et al, 2016] based on air speed, water density and leading edge diameter. Using this approach, it was found that the match between the total amount and chordwise location of accreted ice was significantly improved between the altitude and sea level conditions.

Further analysis of the data from the first and second campaigns suggested that a relationship exists between the water loading and evaporative mass transfer of the runback water and that improved scaling may be possible by matching the relative amounts of the two. In addition, it was indicated that scaling could be improved further by matching the Weber numbers between altitude and sea level using the respective air density instead of water density, as employed in the second campaign. With the potential improvement for scaling IPS between altitude and sea level conditions, the third campaign was initiated. This paper details the corresponding test methods, results and analysis.

\section{Facility Description}

The AIWT is a specialized closed-loop, low to moderate speed wind tunnel used to simulate in-flight atmospheric icing conditions. The tunnel's standard test section is $22.5 \mathrm{in} \times 22.5 \mathrm{in}\left(506.25 \mathrm{in}^{2}\right)$ and $6 \mathrm{ft}$ long. The airspeed in this test section can vary from about 10 to $195 \mathrm{kts}$. Access panels in the tunnel walls, floor and ceiling provide rapid access to test articles as well as flexibility in their mounting in the test section. Plexiglas windows are commonly installed in the test section to enable photographic or video recording of ice formation and growth. Airspeed in the tunnel is computer-controlled using a variable frequency drive which provides power to the fan's $600 \mathrm{hp}$ motor. Test section flow uniformity and a relatively low turbulence level are enhanced through the use of a honeycomb structure and screen at the entry of the settling chamber.

A heat exchanger located upstream of the tunnel's settling chamber permits rapid changes of air temperature within the test section. The use of a three-way valve to control the flow of chilled trichloroethylene through the heat exchanger permits a high level of temporal stability of air temperature in the tunnel. The closed cell insulation surrounding the tunnel shell assists in the ability to obtain static air temperatures as low as $-40^{\circ} \mathrm{C}$. A thick steel tunnel shell combined with the operation of vacuum pumps permits partial evacuation of the air from the tunnel to simulate flight at altitudes as high as $40,000 \mathrm{ft}$.

Six spray bars are located at the entry to the settling chamber, just downstream of the turbulence reduction screens. Up to 5 of 7 spray nozzles in each spray bar may be selected at any one time in various patterns to ensure adequate spray coverage across the test section. By varying the flow rate of distilled water to the external-mix spray nozzles, the liquid water content (LWC) in the test section may be varied between 0.1 and $2.5 \mathrm{~g} / \mathrm{m}^{3}$. Controlling the spray air pressure permits the median volumetric diameter (MVD) of the spray droplet size distribution to vary between 8 and $200 \mu \mathrm{m}$. Additional details regarding the tunnel are provided in [Oleskiw et al. 2001]. 


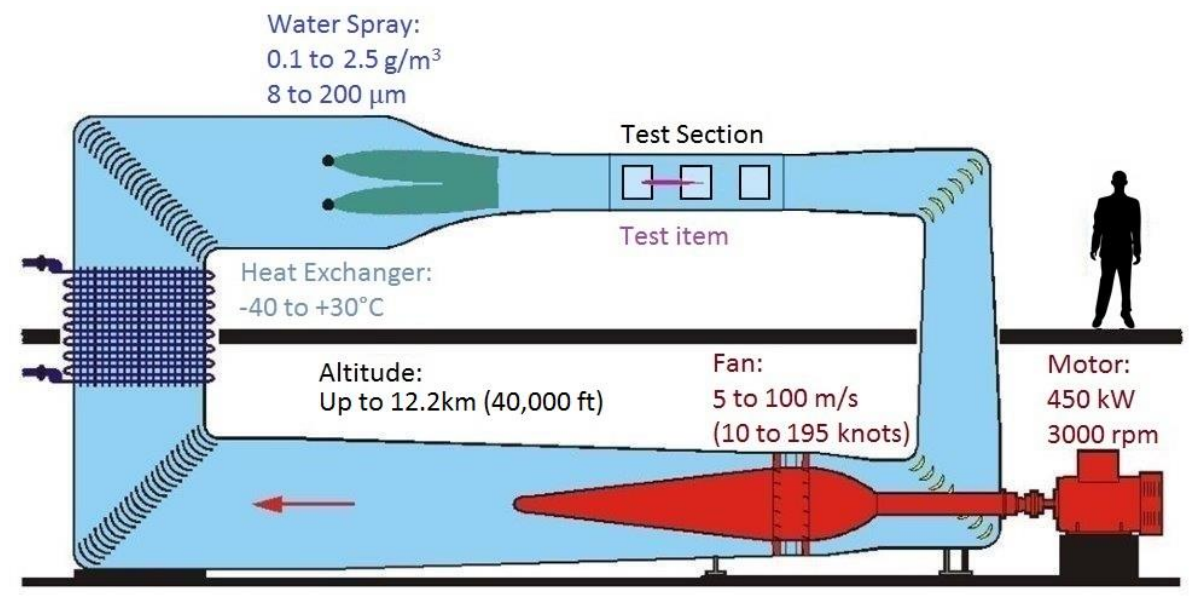

Figure 1: The NRC Altitude Icing Wind Tunnel

\section{Model Description}

The airfoil model used for this study was an 18-inch chord NACA-0018, as it is a symmetric airfoil with a wide leading edge, allowing space for installation of an ice protection system and measurement instruments.

A heated-air piccolo tube ice protection system was designed for the model. The primary objective of the design was to provide a $2 \mathrm{D}$ heating system with minimal span-wise variation in the temperature and heat transfer profiles during testing. To achieve high efficiencies, typical heated-air ice protection system designs result in highly threedimensional thermodynamic profiles that are difficult to measure and analyze accurately. For these reasons, the forward edge of the full-span piccolo tube was located 1.25 inches from the inside of the leading edge and had a single, straight row of 42, 0.032-inch diameter holes spaced 31/64 inches apart. A steel diffuser was designed to direct the heated airflow to and around the inside of the leading edge. Four aluminum ribs were used to maintain the diffuser shape. A graphical representation of the model's thermal protection system is shown in Figure 2.

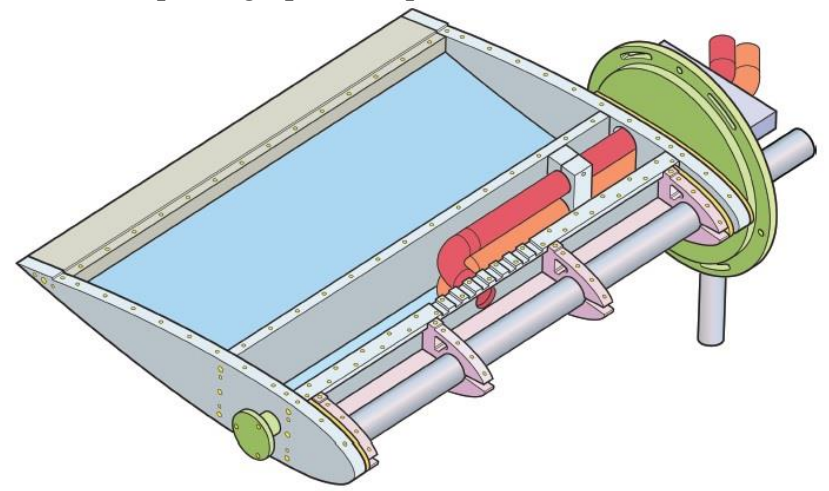

Figure 2: NACA0018 model with piccolo thermal protection system

Heated air was supplied to one end of the piccolo tube where it was directed to the inner surface of the leading edge via the small holes. The heated air was then directed along the inner surface of the leading edge by a symmetric diffuser. The heated air exited the model through exhaust pipes mounted to a spar at the aft of the leading edge. The heated exhaust air flowing from the upper surface was kept separate from that flowing from the lower surface by a horizontal wall extending from the aft of the piccolo tube to the spar. Each of these two exhaust flows were measured by Coriolis flow meters located in the respective exhaust pipes. Manual valves situated downstream of the flow meters were adjusted to ensure proper flow rates maintained equal heating to both the upper and lower surfaces of the leading edge.

Thermocouples were used to measure model surface and heated air temperatures. A total of 25 thin film $(0.0005$ inch thick), T-type thermocouples were installed on the inner surface of the leading edge using a thin layer (approximately 0.002 inches thick) of thermally-conductive epoxy (M-Bond).

Three T-type thermocouples were used to monitor the temperature of the heated air flowing into the model. One was at the entrance to the piccolo tube while two were spaced axially along the center of the tube using a rod device that was inserted into the end of the piccolo tube. Heated air exhaust temperatures were measured using six T-type thermocouples mounted through the front spar. For more information related to the model design see [Addy et al., 2013]. 


\section{Test Conditions}

\section{A. Icing Scenarios}

A set of conditions were selected to approximate three different aircraft icing scenarios at altitude: an aircraft hold at a relatively low icing air temperature (Cold Hold), a hold at a relatively high icing temperature (Warm Hold), and a descent at an intermediate icing temperature (Descent). These conditions are given in Table 1 and will be referred to as reference conditions.

Table 1. Altitude scaling test reference conditions

\begin{tabular}{|c|c|c|c|c|c|c|}
\hline Flight Phase & Altitude, ft. & $\begin{array}{c}\mathbf{V}_{\text {tas, }} \\
\mathbf{k t s}\end{array}$ & $\begin{array}{c}\mathbf{A O A}, \\
\mathbf{d e g}\end{array}$ & $\begin{array}{c}\mathbf{T}_{\text {st, }}, \\
{ }^{\circ} \mathbf{C}\end{array}$ & $\begin{array}{c}\text { LWC, } \\
\mathbf{g} / \mathbf{m}^{\mathbf{3}}\end{array}$ & $\begin{array}{c}\text { MVD, } \\
\boldsymbol{\mu m}\end{array}$ \\
\hline Cold Hold & 15000 & 180 & 0 & -30 & 0.24 & 20 \\
\hline Warm Hold & 15000 & 180 & 0 & -9 & 0.50 & 20 \\
\hline Descent & 10000 & 180 & 0 & -14 & 0.35 & 20 \\
\hline
\end{tabular}

\section{Background}

\section{B. Phase 1: Reynolds number scaling}

When considering the scaling routine to employ during the initial study, it was considered that a method that has some acceptance in the aviation industry be used. For this test, conditions between altitude and sea level are adjusted to maintain the value of four parameters: Reynolds number, water loading, inertia parameter and recovery temperature. This test showed that while the airfoil surface and thermal IPS heat energy were well matched between altitude and sea level, the amount of accreted ice was up to 2 times greater for the sea level conditions than it was at the corresponding altitude case. In addition, the chordwise location of the accreted ice was different with sea level conditions, resulting in ice forming further back along the airfoil surface. This indicated that the amount of runback water and the factors that influence the flow over the surface have a potential impact on the ice formation between altitude and sea level and that an alternative scaling method that brought this into consideration warranted further investigation. Full details of this test program along with results and findings are presented by [Addy et al., 2013].

\section{Phase 2: Weber number scaling}

To consider the potential influence of the runback water on scaling ice accretion between altitude and sea level conditions, an alternative approach was investigated that employs the similarity of Weber number based on air speed $(V)$, water density $\left(\rho_{\mathrm{w}}\right)$, leading edge diameter $(\mathrm{d})$ and surface tension $\left(\sigma_{\mathrm{w}}\right)$, i.e.,

$$
W e=\frac{\rho_{w} V^{2} d}{\sigma_{w}}
$$

This, however, essentially results in a matching of air speed between altitude and sea level conditions as the same model was used for all tests (i.e., diameter remains constant), and water density and surface tension do not vary as a function of altitude. This study demonstrated that this scaling method results in significantly better ice accretions in terms of size, shape and location when compared to the Reynolds number approach. Full details of this test campaign can be found in the NASA Technical Memorandum by [Addy et al., 2016].

\section{Phase 3: Modified Weber number scaling}

Having demonstrated the Weber number approach leads to an improvement in scaling ice accretion size, shape and location, a further analysis of the test data was undertaken to examine the influence of other flow parameters on the operation of IPS at different altitudes.

As a starting point, the difference between mass transport of water due to evaporation at altitude and sea level conditions was examined, where the mass of water that evaporates, $m_{e}$, is approximated by,

$$
\dot{m}_{e}=h_{G}\left(\frac{P_{w w}-P_{w}}{P_{\infty}}\right)
$$


where $P_{w w}$ is the partial pressure of vapour at the surface, $P_{w}$ is the partial pressure of vapour at free stream static conditions, and $\mathrm{P}_{\infty}$ is the static pressure. $h_{G}$ is the gas-phase convective mass transfer coefficient defined as,

$$
h_{G}=\frac{h_{c}}{C_{p, a}}\left(\frac{\operatorname{Pr}}{S c}\right)^{0.67}
$$

where $h_{c}$ is the convective heat transfer coefficient, $C_{p, a}$ the constant pressure specific heat of air. $P r$ and $S c$ are the Prandtl and Schmidt numbers, respectively, defined as,

$$
\begin{aligned}
& \operatorname{Pr}=\frac{C_{p, a} \mu_{a}}{k_{a}} \\
& S c=\frac{\mu_{a}}{\rho_{a} D_{v}}
\end{aligned}
$$

where, $\mu_{a}$ is the dynamic viscosity, $k_{a}$ the thermal conductivity, $\rho_{a}$ the density and $D_{v}$ the diffusivity of water vapour in air. As mass transport is seen as a function of static pressure, the amount of runback water that evaporates would be greater at altitude conditions than at sea level. It was, therefore, considered that the amount of water that runs back along the airfoil surface, to the point at which it freezes, is a function of the loading of impinging water at the leading edge as well the loss of water that subsequently occurs due to evaporation. The loading of impinging water is proportional to the product of Liquid Water Content, $L W C$, collection efficiency at the stagnation point, $\beta_{0}$, and freestream velocity, $V$, e.g.,

$$
m_{w}=L W C \beta_{0} V
$$

To examine this, the ice mass measurements from the second test campaign were compared to the ratio of water loading, $m_{w}$, to mass of water that evaporates $m_{e}$. This ice mass ratio is referred to, for brevity, as $\pi_{3}$ consistent with nomenclature of [Lee et al. 2017], i.e.,

$$
\pi_{3}=\frac{m_{w}}{m_{e}}
$$

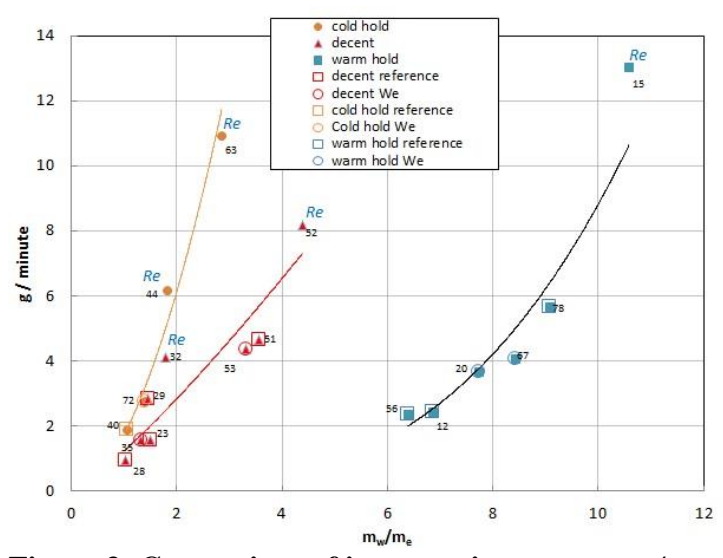

Figure 3: Comparison of ice accretion rate to $m_{w} / m_{e}$
The relationships between the ice mass and the $\pi_{3}$ ratio for the warm hold, cold hold and descent conditions are shown in Error! Reference source not found. and indicate that, for each of the three flight scenarios, the ice accretion rate, determined from the total ice mass measured divided by the exposure time, increases with an increase in ice mass ratio, $\pi_{3}$.

As shown, while there is an observed relationship between the ice mass ratio and rate of accretion, this is segregated between the three flight scenarios and suggests further parameters should be considered for scaling between different altitudes and environmental conditions.

As part of the test procedures, the model surface temperature was maintained constant throughout all tests by adjusting the heated airflow rate into the piccolo tube. This results in variation of convective heat transfer, $q_{c}$, between the three flight scenarios due the changes made in freestream static temperatures, where $q_{c}$ is defined as,

$$
q_{c}=h_{c}\left(T_{\text {surface }}-T_{\text {static }}\right)
$$


In addition, the variation of air density between the reference (elevated altitude) and scaled cases (sea-level) would modify the inertial force exerted to the runback water over the heated section of the airfoil, a parameter that is defined by the Weber number based on air density, $W e_{a}$, i.e.,

$$
W e_{a}=\frac{\rho_{a} V^{2} d}{\sigma_{w}}
$$

where $\rho_{a}$ is the density of the freestream air. Consequently, the relationship of ice mass accretion rate, $m_{i}$, as a function of water loading, $m_{w}$, evaporative mass transfer, $m_{e}$, convective heat transfer and Weber number, $W e_{a}$ was then examined, i.e.,

$$
\text { Accreted Ice Mass } \propto \frac{m_{w}}{m_{e}} \frac{q_{c}}{W e_{a}}
$$

To investigate this extended scaling method, the ratio given in equation 11 was applied to data from the $2^{\text {nd }}$ test campaign and, as shown Error! Reference source not found., suggests a relationship to ice mass accretion is provided.

\section{Test Procedure}

For this test phase, the scaling parameters given in Table 2 were matched.

Matching $W e_{a}$ would result in a higher Reynolds number for sea level conditions than obtained at the reference altitude conditions and, consequently, heat transfer rates would increase. To counter this, a two-step process was adopted to enable surface heat transfer rates to be maintained; this required the matching the leading edge surface temperature through a two-step process, i.e.,

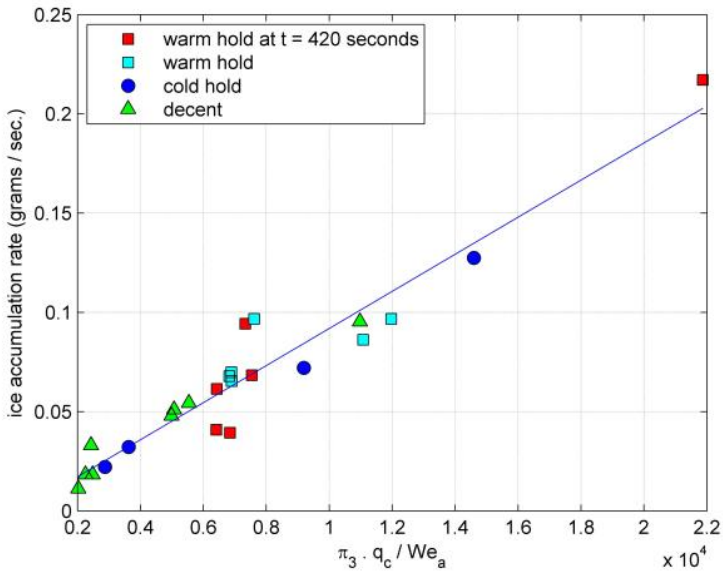

Figure 4: Relationship of extended scaling ratio to ice mass accretion rate from Phase 2 test campaign

1. A test run with Reynolds number scaling to achieve heat transfer similarity and, therefore, surface temperatures for use in the second step and,

2. A test run with Weber number scaling to get ice accretion similarity with a reset thermal IPS to obtain the surface temperatures of the first step.

The reference and scale conditions used for this study are provided in Table 3.Error! Reference source not found.

Table 2. Matched scaling parameters

\begin{tabular}{|l|c|}
\hline \multicolumn{2}{|c|}{ Parameter } \\
\hline Weber number & $W e_{a}$ \\
\hline Mass ratio, $\left(m_{w} / m_{e}\right)$ & $\pi_{3}$ \\
\hline Water loading & $m_{w}$ \\
\hline Evaporative mass transfer & $m_{e}$ \\
\hline Modified inertia parameter, $f\left(\right.$ Re $\left._{\text {drop }}\right)$ & $K_{0}$ \\
\hline Recovery temperature & $T_{r}$ \\
\hline Leading edge surface temperature & $T_{\text {surface }}$ \\
\hline
\end{tabular}


Table 3. Reference and scale conditions (bold denotes matched parameters)

\begin{tabular}{|c|c|c|c|c|c|c|c|c|c|c|}
\hline $\begin{array}{l}\text { Flight } \\
\text { Phase } \\
\end{array}$ & $\begin{array}{c}\text { Alt. } \\
\text { ft. }\end{array}$ & $\begin{array}{c}\mathrm{V} \\
\text { kts }\end{array}$ & $\begin{array}{c}\mathbf{T}_{\text {static }} \\
{ }^{\mathbf{O}} \mathbf{C} \\
\end{array}$ & $\begin{array}{l}\mathbf{L W C} \\
\mathrm{g} / \mathrm{m}^{3} \\
\end{array}$ & $\begin{array}{c}\text { MVD } \\
\mu \mathrm{m}\end{array}$ & $\begin{array}{c}\text { Re-2xr } \\
\text { X10 }^{6} \\
\end{array}$ & Wea & $\begin{array}{c}\pi_{3} \\
m_{w} / m_{e} \\
\end{array}$ & $\mathbf{K}_{\mathbf{0}}$ & $\begin{array}{l}\mathbf{T}_{\mathbf{r}} \\
{ }^{\mathbf{o}} \mathbf{C} \\
\end{array}$ \\
\hline $\begin{array}{l}\text { Descent } \\
\text { (ref) }\end{array}$ & 10000 & 180 & -14.2 & 0.34 & 19.5 & 1.53 & 4026 & 0.7575 & 1.36 & -10 \\
\hline $\operatorname{Re}(\mathrm{sc})$ & SL & 131 & -12.3 & 0.47 & 23.8 & 1.53 & 2971 & 1.0718 & 1.36 & -10 \\
\hline $\mathrm{We}_{\mathrm{a}} \pi_{3}(\mathrm{sc})$ & SL & 158 & -13.2 & 0.30 & 22.1 & 1.82 & 4026 & 0.7575 & 1.36 & -10 \\
\hline Cold Hold & 15000 & 180 & -21.1 & 0.24 & 17.4 & 1.3 & 3397 & 0.2952 & 1.22 & -17 \\
\hline $\operatorname{Re}(\mathrm{sc})$ & SL & 109 & -18.7 & 0.40 & 23.8 & 1.3 & 2130 & 0.5192 & 1.22 & -17 \\
\hline $\mathrm{We}_{\mathrm{a}} \pi_{3}(\mathrm{sc})$ & SL & 143 & -19.7 & 0.20 & 21.4 & 1.69 & 3397 & 0.2952 & 1.22 & -17 \\
\hline $\begin{array}{c}\text { Warm Hold } \\
\text { (ref) }\end{array}$ & 15000 & 180 & -8.6 & 0.49 & 17.5 & 1.26 & 3231 & 2.6383 & 1.22 & -5 \\
\hline $\operatorname{Re}(\mathrm{sc})$ & SL & 106 & -6.1 & 0.83 & 24.2 & 1.26 & 1924 & 4.7104 & 1.22 & -5 \\
\hline $\mathrm{We}_{\mathrm{a}} \pi_{3}(\mathrm{sc})$ & SL & 139 & -7.0 & 0.41 & 21.8 & 1.63 & 3132 & 2.6383 & 1.22 & -5 \\
\hline
\end{tabular}

\section{Results}

\section{A. Descent case}

As shown in Table 4, the We $\pi_{3}$ sea level scaling provides a markedly improved comparison to the ice mass of the altitude reference case when compared to that provided by the Re scaling. Here the $\mathrm{We} \pi_{3}$ scaling method resulted in a $11 \%$ difference in ice mass when compared to that obtained at altitude conditions, whereas the $\mathrm{Re}$ scaling provided ice mass over $500 \%$ that of the reference. In addition, pictures of the upper surface of the airfoil given in Figure 5 and ice tracings given in Figure 6 show that chordwise location and height of ice when applying the We $\pi_{3}$ sea level scaling matches well with the altitude reference conditions. For the Re scaling method, however, the height of the ice is increased and is shown to form further aft, a result that is consistent with the findings of the previous studies [Addy et al., 2013, 2016].

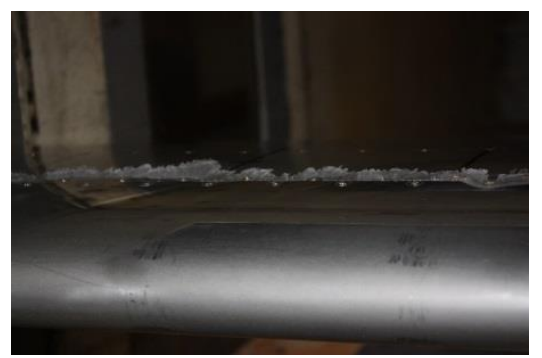

a) Reference (Altitude $=\mathbf{1 0 , 0 0 0} \mathrm{ft}$ )

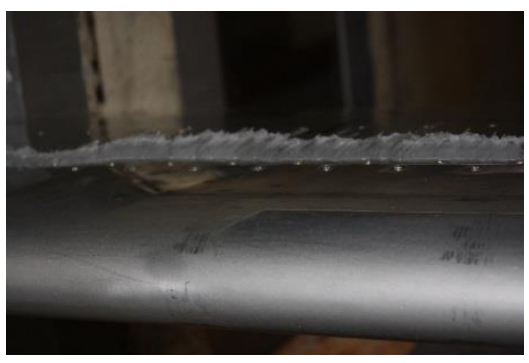

b) Re-scaled (Altitude = SL)

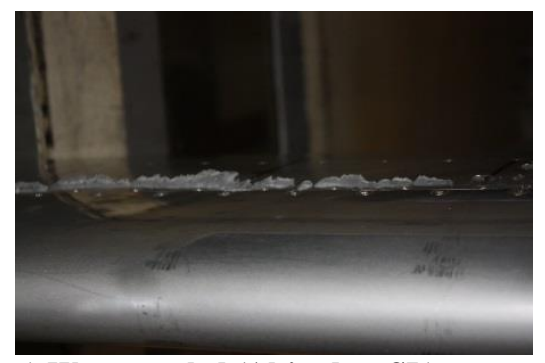

c) $\mathrm{We}_{\mathrm{a}} \pi_{3}$ scaled (Altitude $\left.=\mathrm{SL}\right)$

Figure 5. Images of ice accetion for descent condition cases at $10 \mathrm{kft}$ altitude and sea level with $\mathrm{Re}$ and Wea $\pi_{3}$ applied.

Figure 7 shows the model surface temperatures during the run both before exposing the model to the cloud (dry) and again during exposure to the cloud (wet). The close agreement between the reference and scale temperatures in the dry conditions indicate the degree to which the two step method described above enables matching of heat transfer rate between altitude and sea level conditions. For surface temperatures with spray on conditions (wet), the 
Re and We $\pi_{3}$ cases have surface temperatures slightly higher than the reference case particularly at the leading edge, an observation similar to that of [Addy et al., 2013] and was considered a result of increased evaporative cooling for the reference case.

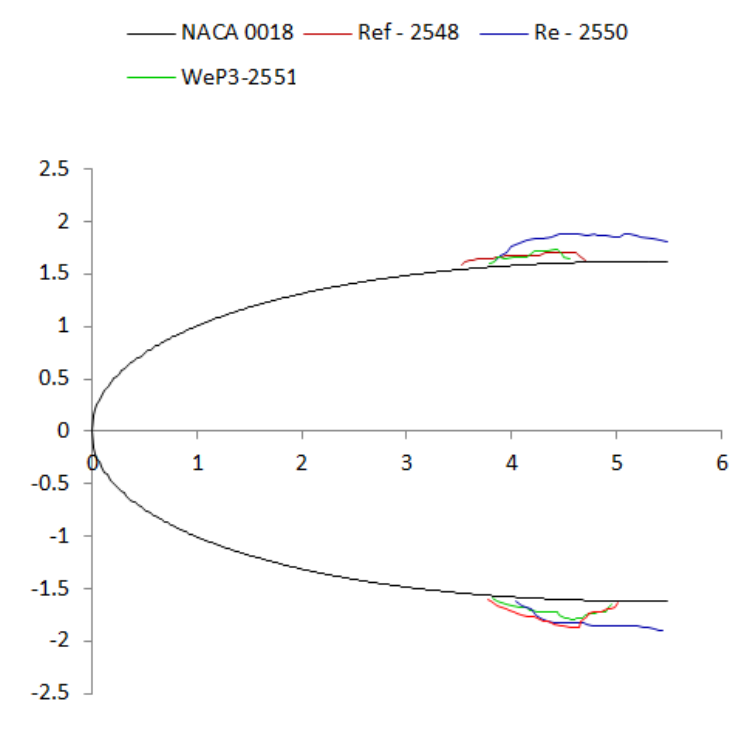

Figure 6: Ice tracing from descent case reference and Re and We- $\pi 3$ scaled conditions

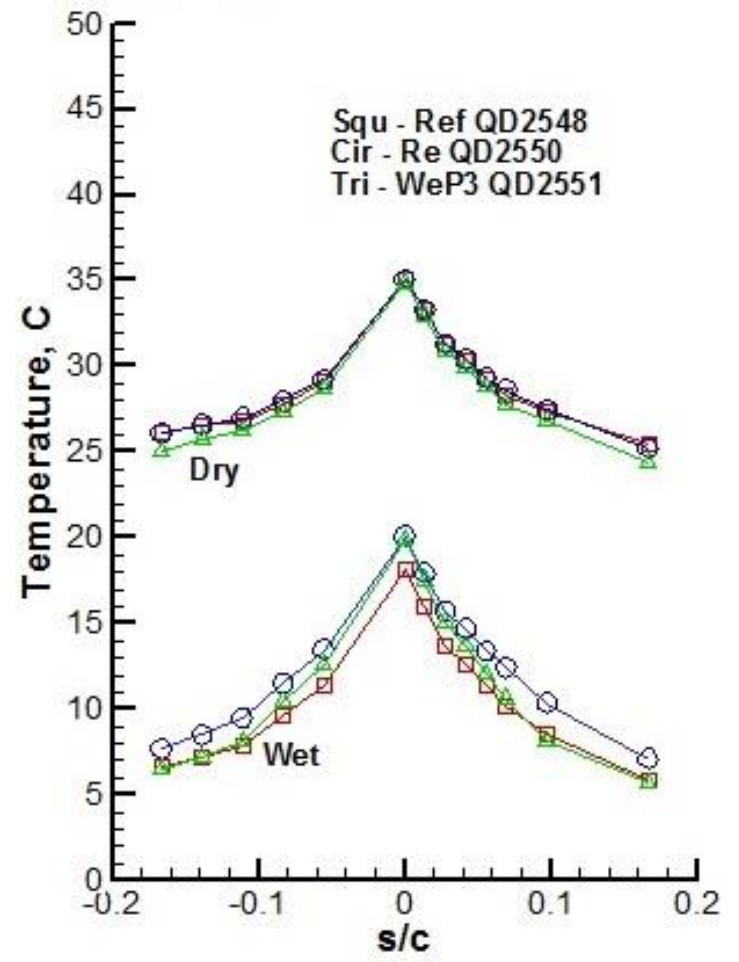

Figure 7: Surface temperature profiles from descent case reference and $\mathrm{Re}$ and $\mathrm{We}-\pi 3$ scaled conditions

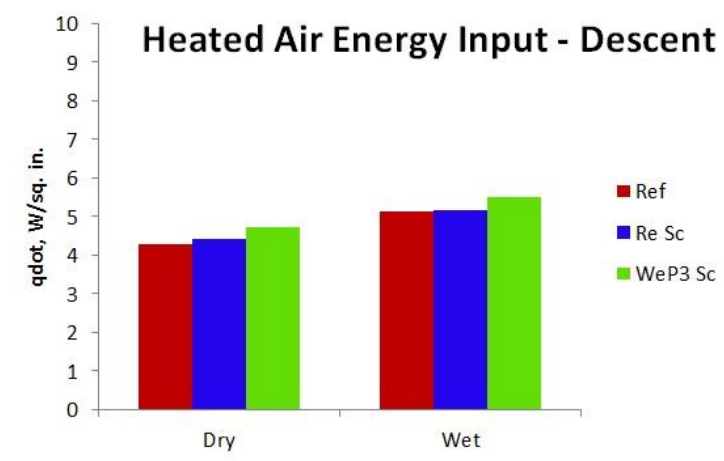

b) IPS energy input for descent conditions

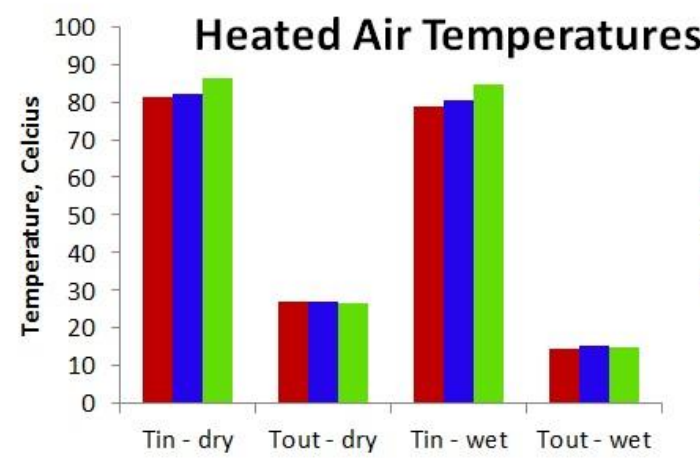

a) IPS air temperatures for descent conditions
@ Reference

- $\mathrm{Re}-\mathrm{Sc}$

We $-\mathrm{Sc}$

\section{Figure 8: IPS operational data from descent case reference, Re and We- $\pi_{3}$ scaled conditions}

The measured reference and scale IPS heated air inlet and outlet temperatures along with the heat energy used for both the dry and wet conditions for the descent case are shown in Figure 8. As expected, the Re-scaling inlet temperatures and energy input are nearly identical to the reference condition values; however, the inlet temperatures and energy input from the We $\pi_{3}$ scaling method are higher as a result of the increased thermal energy required to maintain the leading edge temperature at the higher Reynolds numbers (and hence higher convective cooling). Similar results were obtained in the previous AIWT study using We scaling based on water density [Addy et al., 2016] and in larger scale thermal protection system scaling tests performed in the NASA Glenn Icing Research 
Tunnel (IRT) [Lee et al., 2017]. Much smaller differences in the outlet temperature are observed between the Rebased and We-based scaling methods.

\section{B. Cold Hold}

As shown in Table 5, as with the descent scaling, the We $\pi_{3}$ sea level scaling provides improved comparison to the ice mass of the altitude reference case when compared to the Re scaling method that shows nearly an $800 \%$ times increase in the mass of ice formed. In addition, pictures of the upper surface of the airfoil given in Figure 9 and ice tracings given in Figure 10 show that improved chordwise location and height of accreted ice mass are obtained when applying the We $\pi_{3}$ sea level scaling.

Table 5. Cold Hold run conditions and ice mass measurements

\begin{tabular}{|c|c|c|c|c|c|c|c|c|}
\cline { 2 - 9 } \multicolumn{1}{c|}{} & Alt & $\mathbf{P}_{\text {alt }}$ & $\mathbf{V}$ & $\mathbf{T}_{\mathbf{s}}$ & $\mathbf{L W C}$ & $\mathbf{M V D}$ & $\boldsymbol{\tau}$ & Ice \\
\cline { 2 - 9 } \multicolumn{1}{c|}{} & $\mathbf{f t}$ & $\mathbf{p s i}$ & $\mathbf{k t}$ & ${ }^{\circ} \mathbf{C}$ & $\mathbf{g}^{\mathbf{3}} \mathbf{m}^{3}$ & $\boldsymbol{\mu m}$ & $\mathbf{s}$ & $\mathbf{g}$ \\
\hline Ref & 15000 & 8.3 & 180 & -20.1 & 0.24 & 17.4 & 1200 & 8.2 \\
\hline $\boldsymbol{R e}-\mathbf{s c}$ & 713 & 14.6 & 106 & -17.5 & 0.41 & 24.7 & 1200 & 65.2 \\
\hline We $\boldsymbol{\pi}_{3}$-sc & 1363 & 14.5 & 142 & -18.5 & 0.20 & 21.6 & 1200 & 6.1 \\
\hline
\end{tabular}

As with the descent case, the temperature profiles for the dry (spray off) conditions, shown in Figure 11, are consistent for altitude and (both) scaled cases. For the wet (spray on) conditions, however, the surface temperature profile for We $\pi 3$ and Re scaling are (generally) higher than those of the reference case. This increase is larger than that observed for the descent case and, again, may be a result of the increase in evaporative cooling at the higher altitude $(15,000 \mathrm{ft})$ used for the cold hold reference.

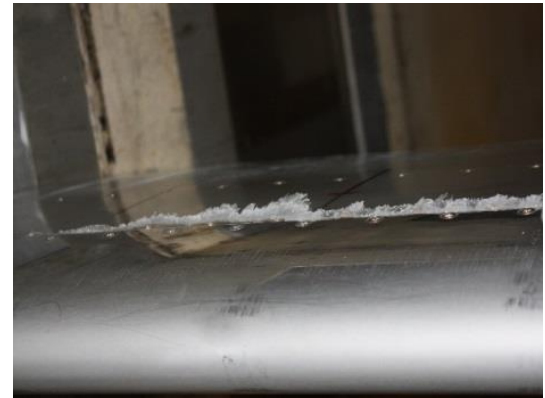

a) Reference (Altitude $=\mathbf{1 5 , 0 0 0 ~ f t )}$

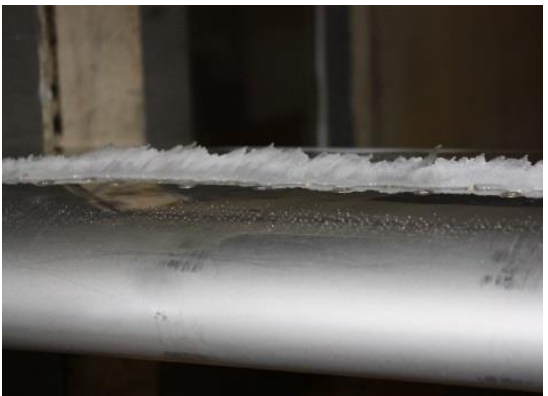

b) Re-scaled (Altitude $=$ SL)

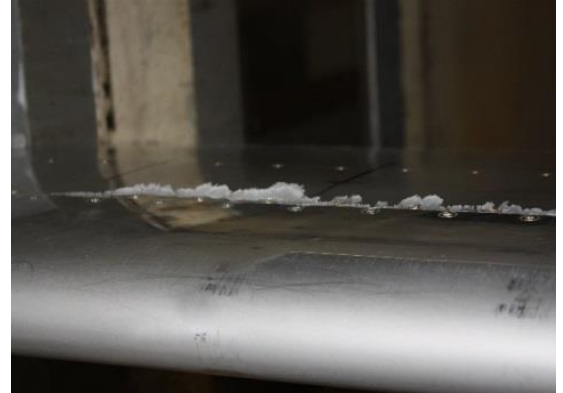

c) $\mathrm{We}_{\mathrm{a}} \pi_{3}$ scaled (Altitude $=\mathrm{SL}$ )

Figure 9: Images of ice accretion for cold hold condition cases at $15 \mathrm{kft}$ altitude and sea level with Re and $\mathrm{We}_{\mathrm{a}} \pi_{3}$ applied.

Consistent with the IPS temperature and heat energy measurements from the descent cases, the values given in Figure 12 show higher input temperature and heat energy for the We $\pi_{3}$ scaling method when compared to the reference and Re scaling approach. 


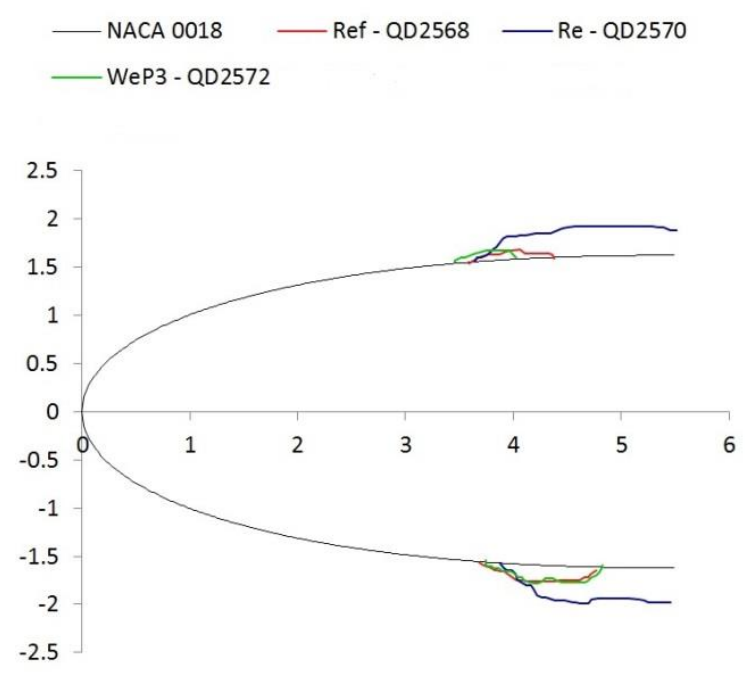

Figure 10: Ice tracing from cold hold case reference and Re and We- $\pi_{3}$ scaled conditions

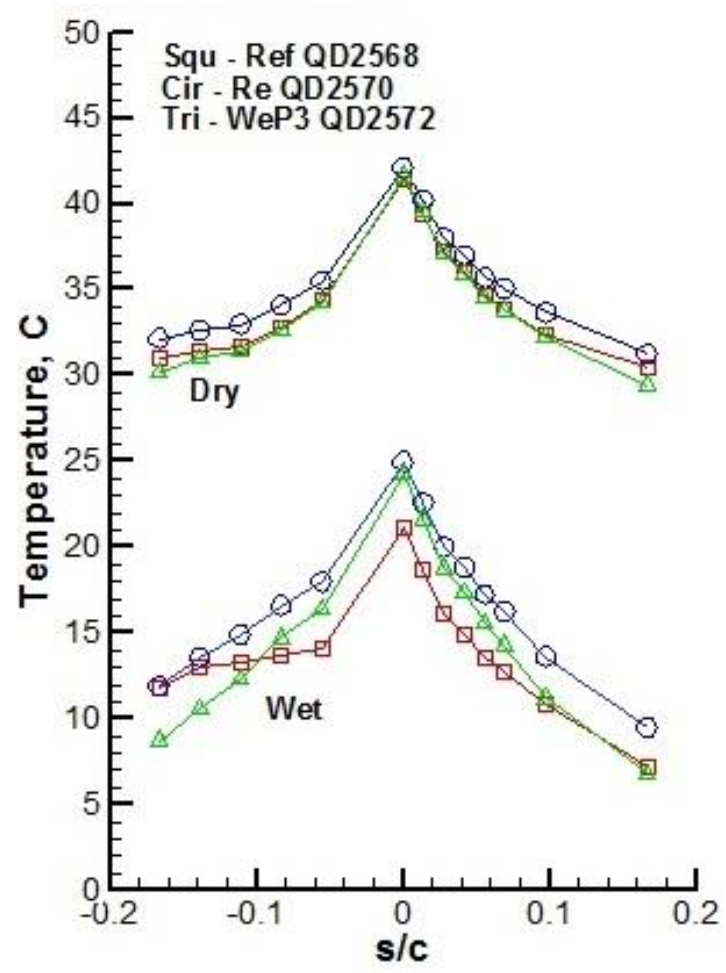

Figure 11: Surface temperature profiles from cold hold case reference and $\mathrm{Re}$ and $\mathrm{We}-\pi_{3}$ scaled conditions

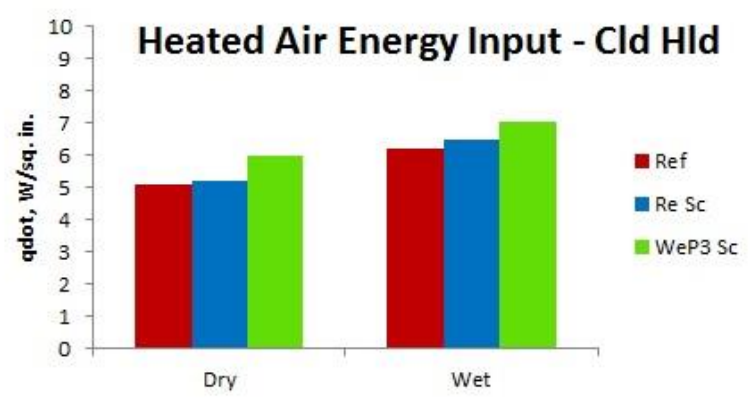

b) IPS energy input for cold hold conditions

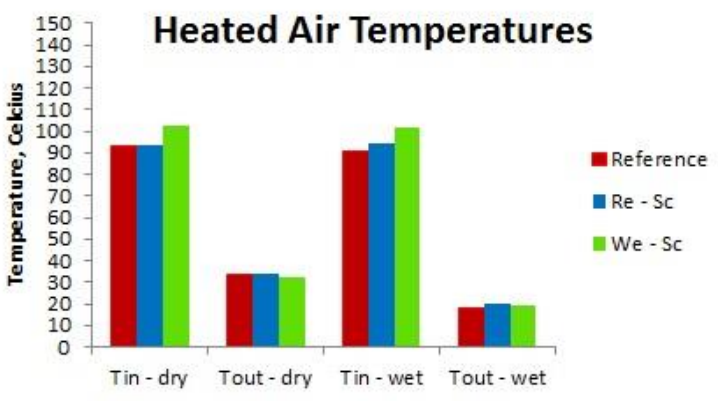

a) IPS air temperatures for cold hold conditions

Figure 12. IPS operational data from cold hold case reference, Re and We- $\pi 3$ scaled conditions

\section{Warm Hold}

As shown in Table 6 , the We $\pi_{3}$ sea level scaling provides an improved matching of ice mass obtained at altitude conditions when compared to the $\mathrm{Re}$ scaling method, which shows an almost $300 \%$ increase in the mass of ice formed compared to a $40 \%$ increase for $\mathrm{We} \pi_{3}$. In addition, pictures of the upper surface of the airfoil given in Figure 13 and ice tracings given in Figure 14 show that improved matching chordwise location,
Table 6. Warm hold run conditions and ice mass measurements

\begin{tabular}{|c|c|c|c|c|c|c|c|c|}
\cline { 2 - 9 } \multicolumn{1}{c|}{} & Alt & $\mathbf{P}_{\text {alt }}$ & $\mathbf{V}$ & $\mathbf{T}_{\mathbf{s}}$ & $\mathbf{L W C}$ & $\mathbf{M V D}$ & $\boldsymbol{\tau}$ & Ice \\
\cline { 2 - 9 } \multicolumn{1}{c|}{} & $\mathbf{f t}$ & $\mathbf{p s i}$ & $\mathbf{k t}$ & $\mathbf{o}^{\mathbf{o}}$ & $\mathbf{g} / \mathbf{m}^{\mathbf{3}}$ & $\boldsymbol{\mu m}$ & $\mathbf{s}$ & $\mathbf{g}$ \\
\hline Ref & 15000 & 8.3 & 180 & -8.5 & 0.49 & 17.5 & 420 & 20.1 \\
\hline $\mathbf{R e}-\mathbf{s c}$ & 733 & 14.6 & 106 & -6.0 & 0.79 & 23.7 & 420 & 58.7 \\
\hline We $\boldsymbol{\pi}_{3}$-sc & 1284 & 14.5 & 140 & -7.1 & 0.44 & 21.5 & 420 & 28.1 \\
\hline
\end{tabular}


height and appearance of ice are obtained when applying the We $\pi_{3}$ sea level scaling.

As with the cold hold conditions, the surface temperature profiles, shown in Figure 15, match well with reference conditions in the dry (spray off) cases, but are elevated for both scaled cases when running in wet (spray on) conditions. Also, as with the previous test conditions, the inlet temperatures and heat energy for the $\mathrm{We}_{\mathrm{a}} \pi_{3}$ approach are higher than the reference or Re scaled values, as shown in Figure 16.

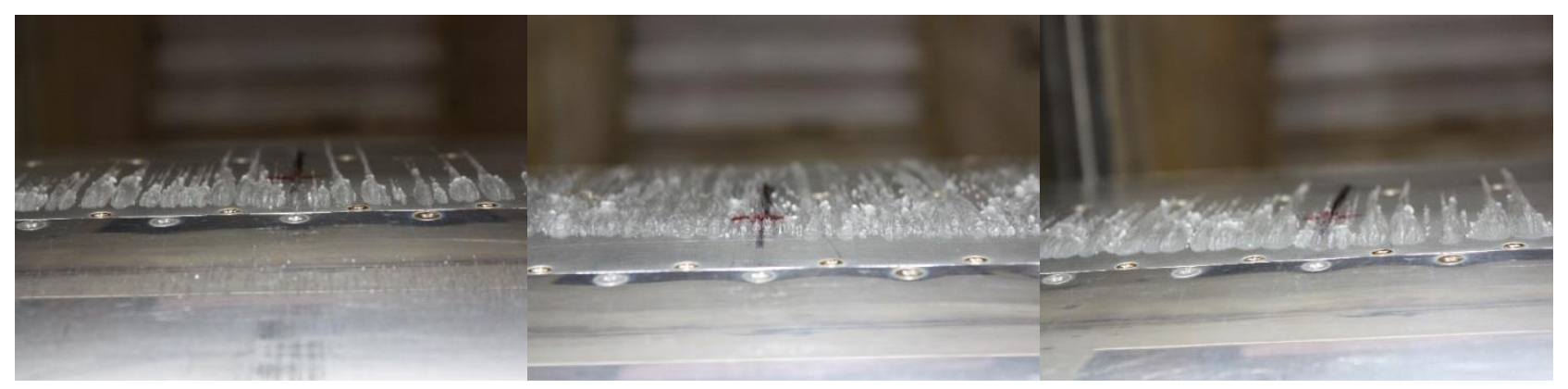
a) Reference (Altitude $=\mathbf{1 5 , 0 0 0 ~ f t )}$
b) Re-scaled (Altitude $=$ SL)
c) $\mathrm{We}_{\mathrm{a}} \boldsymbol{\pi}_{3}$ scaled (Altitude $=\mathrm{SL}$ )

Figure 13. Images of ice accretion for warm hold condition cases at $15 \mathrm{kft}$ altitude and sea level with Re and Wea $\pi_{3}$ applied.

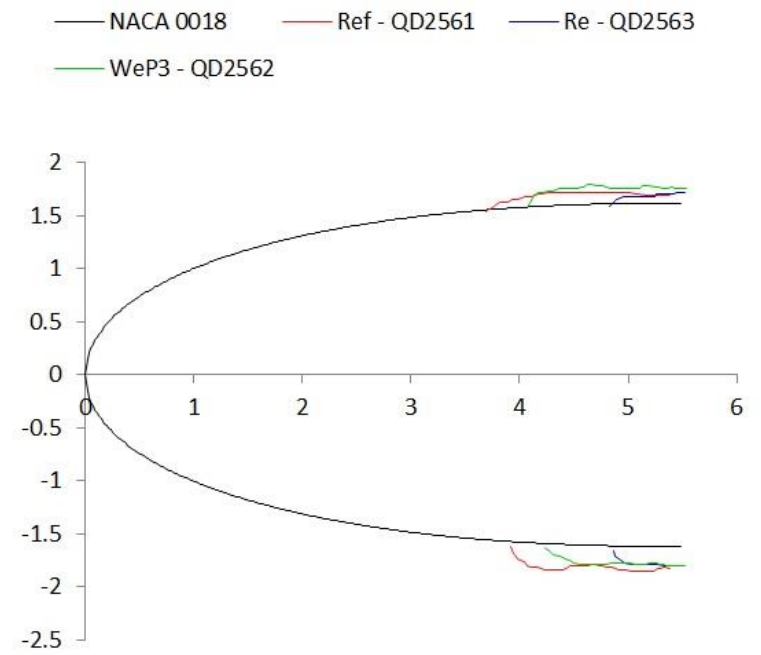

Figure 14: Ice tracing from warm hold case reference and Re and We- $\pi_{3}$ scaled conditions

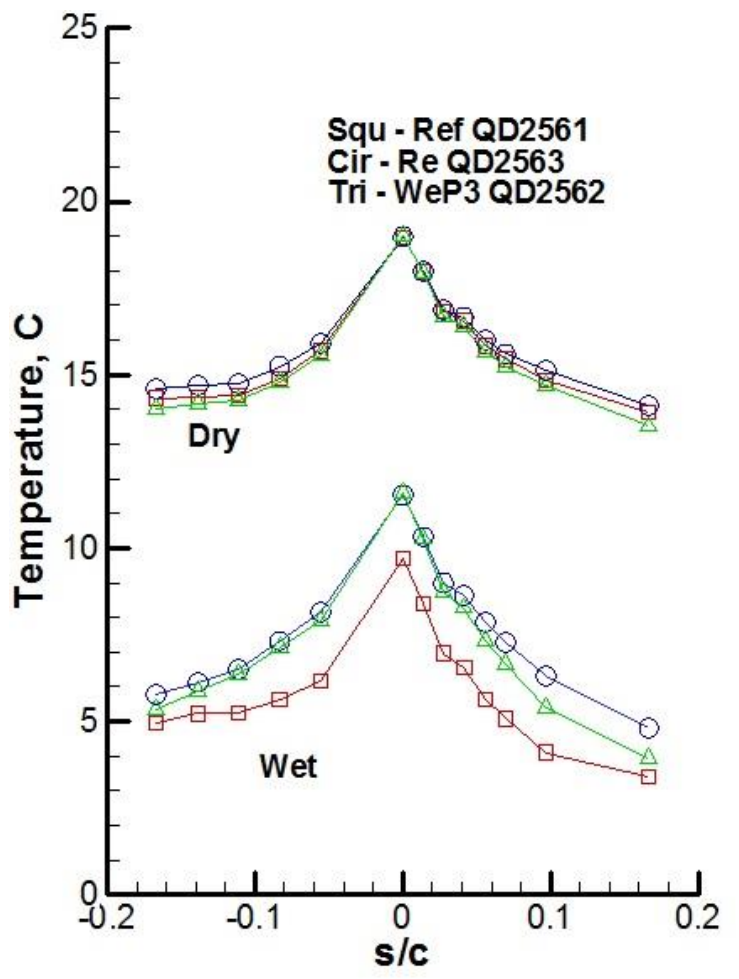

Figure 15: Surface temperature profiles from warm hold case reference and $\mathrm{Re}$ and $\mathrm{We}-\pi_{3}$ scaled conditions 


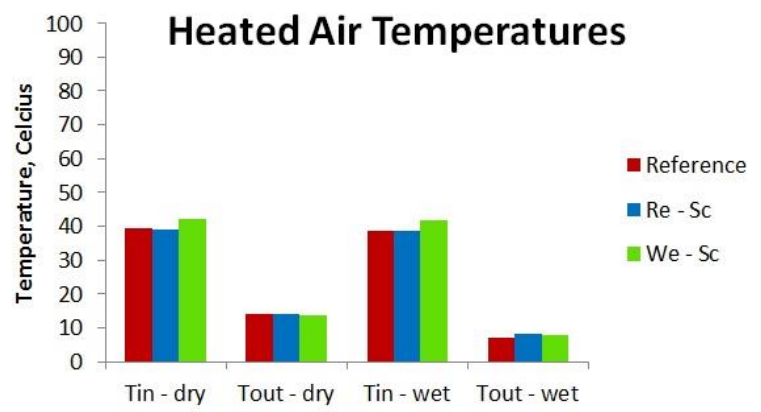

a) IPS air temperatures for warm hold conditions

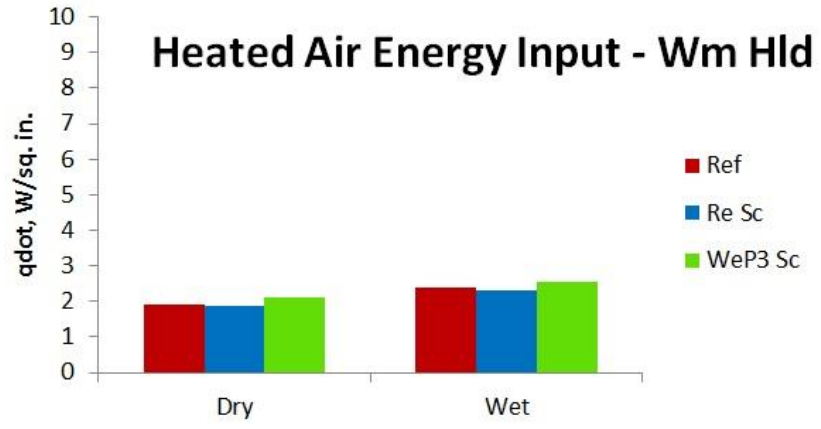

b) IPS energy input for warm hold conditions

Figure 16: IPS operational data from warm hold case reference, Re and We- $\pi_{3}$ scaled conditions

\section{Discussion}

Comparing the data obtained from tests conducted with Reynolds number and water density based Weber number scaling (phase 2 testing) [Addy et al 2016] with that of the current test program, there was a clear difference in the ice mass obtained between the two wind tunnel entries. For example, as shown in Figure 17, the accreted ice mass for the reference conditions from phase 2 differ from those obtained from phase 3. This point is emphasized when it is considered that the surface temperature was required to be lowered in phase 3, as shown in Figure 18: , and the icing cloud exposure extended from 600 to 900 seconds for the descent conditions and 600 to 1200 seconds for cold hold (for warm hold time was held at 420 seconds for both test phases). These changes were required in order to obtain a sufficient ice mass for comparison to scaled sea level conditions. The reason for such differences is unclear but it is considered to arise from the test to test variability in controlling the guard heaters installed at either side of the model in order to maintain two dimensional temperature distributions across the span of the model.

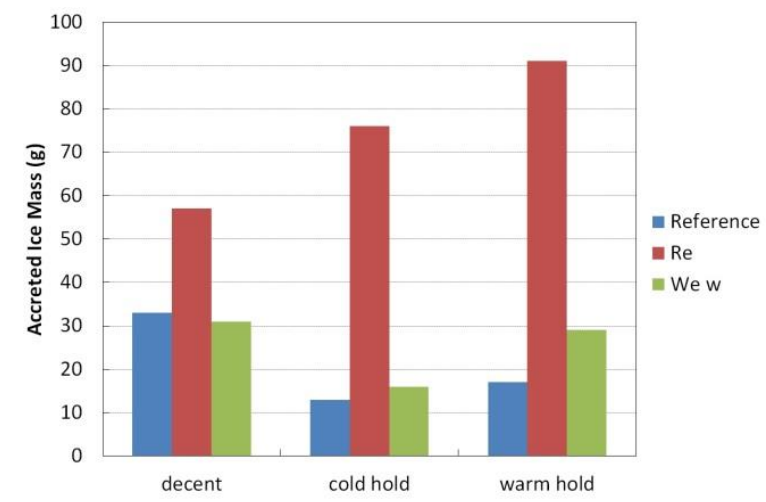

a) Accreted ice mass from phase 2 tests (2014)

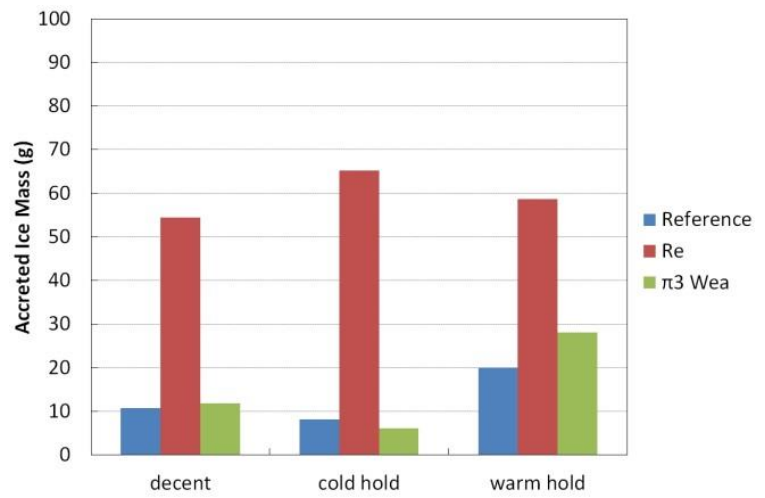

b) Accreted ice mass from phase 3 tests (2015)

Figure 17: Ice mass from descent, cold hold and warm test cases 


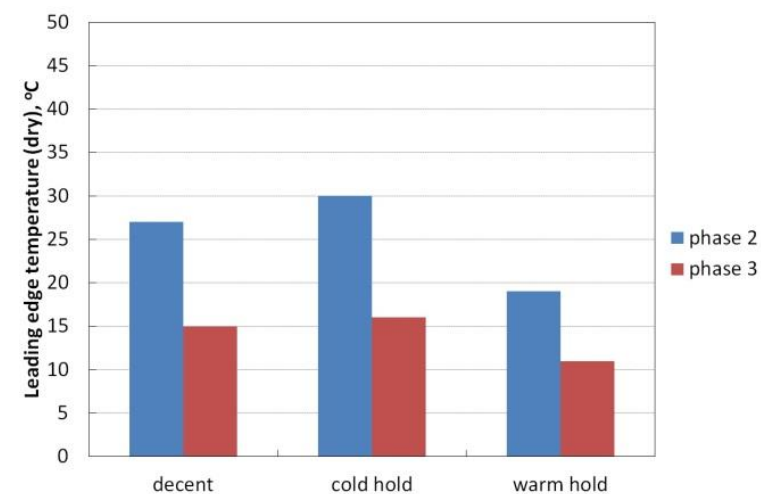

a) Leading edge temperature with spray off

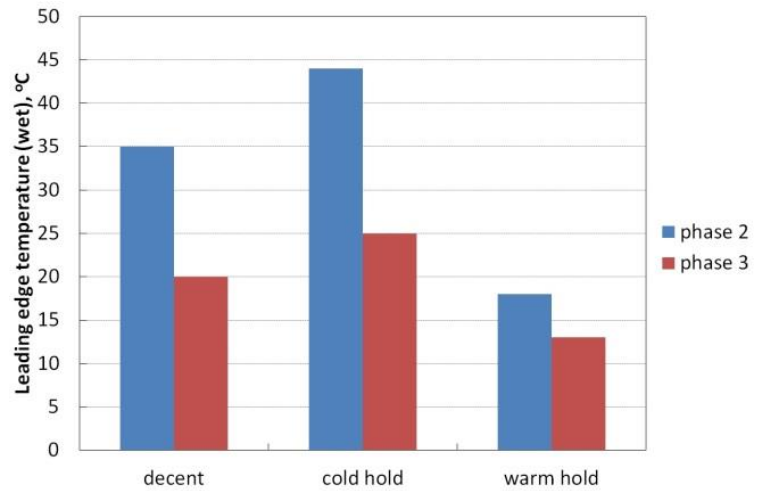

b) Leading edge temperature with spray on

Figure 18: Leading edge temperatures from descent, cold hold and warm hold cases

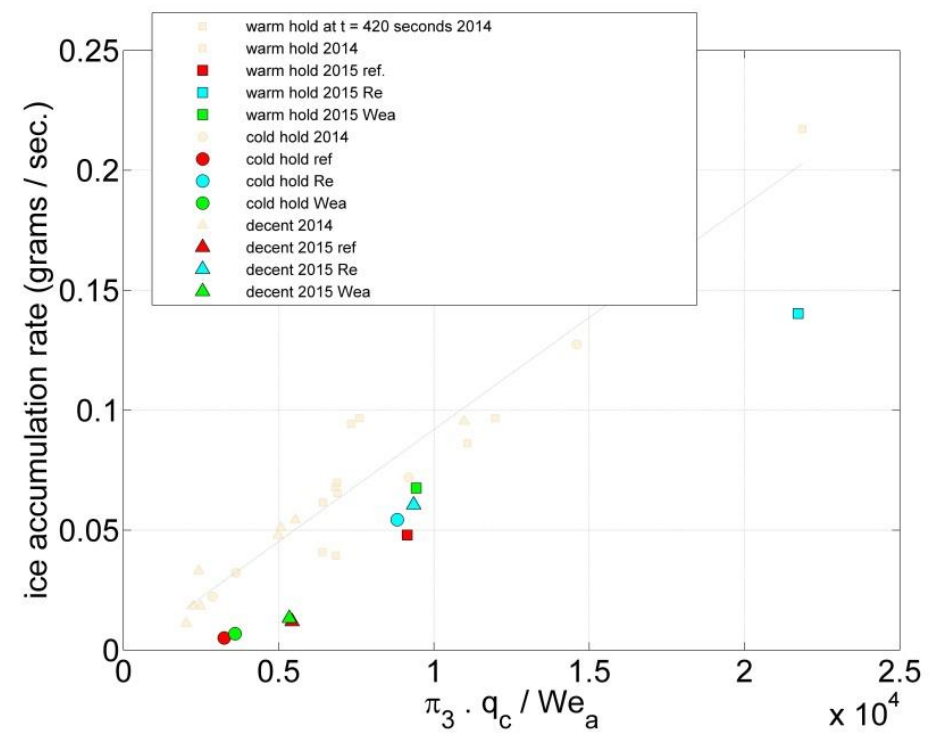

Figure 19. Relationship of extended scaling ratio to ice mass accretion rate from Phase 3 test campaign
The differences discussed above are also seen when comparing the extended scaling ratio to mass accretion rate, as shown in Figure 19. When compared with data from the phase 2 test, while there is a difference in the ice accretion rate, a similar relationship is seen to the scaling ratio. Nevertheless, despite the repeatability issues between test entries, the results demonstrate that Weber number scaling can provide comparable accreted ice mass to the reference conditions at altitude. As shown in Figure 17, water density based Weber number and the $\mathrm{We}_{\mathrm{a}} \pi_{3}$ methods offer similar comparisons in terms of accreted ice mass. Closer examination of the ice tracings (see Figure 6, Figure 10 and Figure 14), however, show that the $\mathrm{We}_{\mathrm{a}}$ $\pi_{3}$ scaling method has the potential to offer improved matching of ice shape and chordwise location.

During the phase 1 study [Addy et al., 2013], it was observed that some water drops running back over the airfoil surface would settle in regions where conditions permitted freezing. In these areas, as shown in Figure 20, both ice and liquid water were observed in the form of drops on top of the ice. Periodically, the drops would disappear. It was considered that this may be due to water being re-entrained back into the air flow. While Weber number scaling would provide an improved match of this phenomenon between altitude and sea level, the relationship of the We $\mathrm{W}_{3}$ parameter to ice accretion rates shown in Error! Reference source not found. and Figure 19 would suggest a further mechanism is at play related to the mass and thermal transport properties of the water film as it runs back to the location where it freezes. A further study is planned to examine both mechanisms and how they relate to matching of ice accretion between altitude and sea level conditions for running wet thermal ice protection systems. 


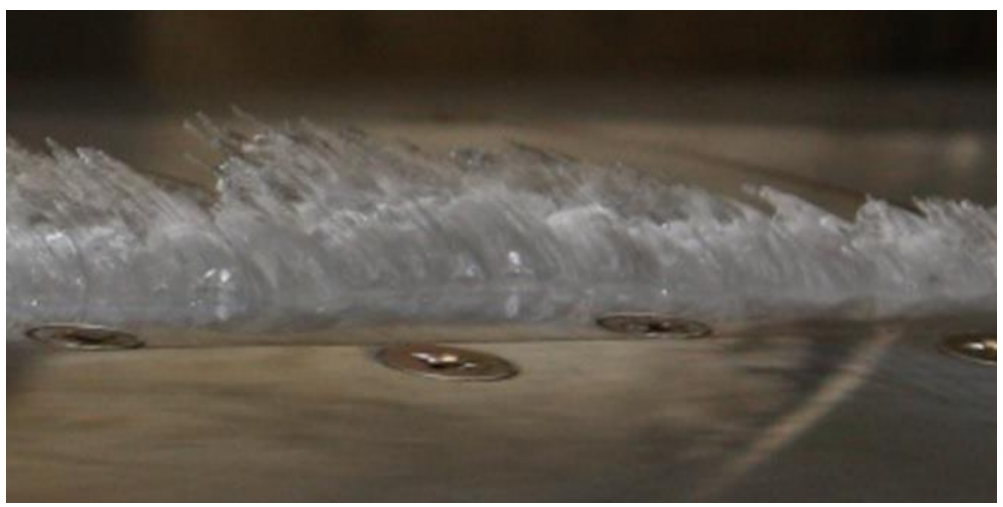

Figure 20. Presence of water drops on top of ice for decent reference condition

\section{Conclusion}

A test on various methods for scaling ice accretion over airfoils operating thermal protection systems, in a running wet mode, has been performed in the Altitude Icing Wind tunnel of the National Research Council. This was a continuation of collaborative study with NASA Glenn Icing Branch in which various scaling techniques have been employed to obtain similarity between altitude and sea level conditions. While previous studies examined scaling based on Reynolds number and Weber number (water density), analysis suggested there was a relationship between the rate of ice accretion and the ratio of water loading to rate of evaporation, i.e., $M_{w} / M_{e}$. This test, therefore, employed similarity of this parameter between altitude and sea level conditions as well as maintaining Weber number (based on air density) and surface heat transfer rates (achieved through a two step process employing surface temperature matching between scaled Reynolds number and Weber number, $W e_{a}$, conditions). During this study the following was observed;

1. Surface temperatures and heat rejection rates matched well between reference and Re-scaled conditions

2. Re-scaled conditions resulted in greater mass of ice accreted

3. The two-step, $\mathrm{Re} \& \mathrm{We}_{\mathrm{a}} \pi_{3}$ scaling method produced ice accretions similar to those at the reference altitude conditions

\section{References}

Addy, H. E., Broeren, A. P., Oleskiw, M and Orchard, D. M., "A Study of the Effects of Altitude on Thermal Ice Protection System Performance” AIAA conference, June 2013, San Diego, CL, AIAA Paper 2013-2934

Addy, H. E., Orchard, D. M., Wright, W. B., and Oleskiw, M., "Altitude Effects on Thermal Ice Protection System Performance; a Study of an Alternative Approach,” NASA TM-219081, 2016.

Feo, A., "Similarity of Water Film Weber Number and Film Thickness in Icing Scaling," AE/TNO/4420/264/INTA/014, Instituto Nacional de Tecnica Aeroespacial, October 2001.

Kind, R. J., "Assessment of importance of Water-Film Parameters for Scaling of Glaze Icing", $39^{\text {th }}$ AIAA Aerospace Sciences Meeting and Exhibit, January 8-11, 2001, Reno, NV, AIAA Paper 2001-0835.

Kind, R.J., and Oleskiw, M.M., "Experimental Assessment of a Water-Film-Thickness Weber Number for Scaling of Glaze Icing," $39^{\text {th }}$ AIAA Aerospace Sciences Meeting and Exhibit, January 8-11, 2001, Reno, NV, AIAA Paper 2001-0836

Lee, S, Addy, H. E., Broeren, A. P, and Orchard, D. M., "Evaluation of Alternative Altitude Scaling Methods for Thermal Ice Protection System in NASA Icing Research Tunnel", AIAA Atmospheric and Space Environment conference, June 2017, Denver, CO.

Oleskiw, M.M., Hyde, F.H., and Penna, P.J., "In-Flight Icing Simulation Capabilities of NRC's Altitude Icing Wind Tunnel," $39^{\text {th }}$ AIAA Aerospace Sciences Meeting and Exhibit, January 8-11, 2001, Reno, NV,AIAA-2001-0094 
Olsen, W., and Walker, E., "Experimental Evidence for Modifying the Current Physical Model for Ice Accretion on Aircraft Surfaces," NASA TM-87184, January 1987.

Papadakis, M., Wong, S.H., Yeong, H.W., Wong, S.C., and Vu, G.T., "Icing Tunnel Experiments with a Hot Air Anti-Icing System," 46 ${ }^{\text {th }}$ AIAA Aerospace Sciences Meeting and Exhibit, January 7-10, 2008, Reno, NV, AIAA Paper 2008-444.

SAE AIR6440, "Icing Tunnel Tests for Thermal Ice Protection Systems", SAE AC-9C Aircraft Icing Technology Committee, June 2014

Whalen, E.A., Broeren, A.P., and Bragg, M.B., "Characteristics of Runback Ice Accretions on Airfoils and their Aerodynamic Effects," 43 ${ }^{\text {rd }}$ AIAA Aerospace Sciences Meeting and Exhibit, January 10-13 2005, Reno, NV, AIAA Paper 2005-1065.

Whalen, E.A., Broeren, A.P., and Bragg, M.B., "Characteristics of Runback Ice Accretions and their Aerodynamic Effects,”FAA Report DOT/FAA/AR-07/16, April 2007.

\section{Acknowledgements}

The authors would like to acknowledge the work of the AIWT tunnel operator, Gislain Chevrette, for his advice and tireless efforts in the setup and operation of the test program. They were instrumental to the efficient use of the facility and successful completion of the test campaign. 